\title{
Impact of cell culture methods on the outcomes of the in vitro inflammatory response in nasal polyps*
}

\author{
Laura Fernández-Bertolín ${ }^{1,2}$, Joaquim Mullol ${ }^{1,2,3}$, Isam Alobid ${ }^{1,2,3}$, \\ Jordi Roca-Ferrer ${ }^{1,2}$, César Picado ${ }^{1,2,4}$, Laura Pujols ${ }^{1,2 \S}$ \\ 1 Institut d'Investigacions Biomèdiques August Pi i Sunyer (IDIBAPS), Barcelona, Spain \\ 2 Centro de Investigaciones Biomédicas en Red de Enfermedades Respiratorias (CIBERes), Barcelona, Spain \\ 3 Unitat de Rinologia i Clínica de l'Olfacte, Servei d'Otorinolaringologia, Hospital Clínic, Barcelona, Spain \\ ${ }_{4}$ Servei de Pneumologia i Al·lèrgia Respiratoria, Hospital Clínic, Barcelona, Spain
}

SUMMARY Background: In vitro culture of nasal polyp cells is frequently used in the investigation of inflammatory mechanisms and effect of treatments in nasal polyposis. Research outcomes may, however, be influenced by the culture methodology used.

Methods: Nasal polyp and nasal mucosa in vitro fibroblast cultures were pre-treated with foetal bovine serum (FBS)-free culture medium or medium supplemented with either FBS or charcoal-stripped (cS) FBS. Cells were then stimulated with FBS or csFBS, with or without different doses of dexamethasone for 4 and 24h. IL-6, IL-8, GM-CSF and VEGF release and cell viability were measured.

Results: The highest cytokine levels were found in growth-arrested cells stimulated with $10 \%$ FBS. csFBS poorly stimulated cytokine release. Nasal polyp released larger IL-8 amounts than nasal mucosa fibroblasts. Dexamethasone decreased cytokine production dose- and time-dependently in both nasal mucosa and nasal polyp fibroblasts. The $I C_{25}$ of $I L-8$ inhibition by dexamethasone was higher in nasal polyp than in nasal mucosa fibroblasts. Cell viability did not differ among treatments.

Conclusions: Cytokine production by in vitro cultured nasal fibroblasts is affected by the culture conditions used and is inhibited by dexamethasone in both fibroblast types. Our results highlight the importance of culture methodology on nasal polyp research outcomes.

Key words: cytokines, fibroblasts, glucocorticoids, nasal mucosa, nasal polyps

\section{INTRODUCTION}

Nasal polyposis is a chronic inflammatory disease of the sinus mucosa usually seen in association with chronic rhinosinusitis ${ }^{(1)}$. The pathogenesis of chronic rhinosinusitis with nasal polyps is related to an altered inflammatory state that results in a tissueremodelling process ${ }^{(2)}$. The inflammatory response in nasal polyps is associated with elevated levels of pro-inflammatory cytokines and growth factors in the nasal tissue. Although eosinophils and Th2-related cytokines dominate the pattern of inflammation in nasal polyps, structural cells such as fibroblasts, as well as non-Th2-related cytokines and growth factors, also contribute to nasal polyp development ${ }^{(3)}$. Fibroblasts can contribute to the regulation of inflammatory and immunological responses by producing various growth factors and cytokines ${ }^{(4,5)}$.

Long-term therapy with intranasal glucocorticoids (GC) is widely used to control nasal polyp inflammation and growth, and also to restore the capacity to smell ${ }^{(6,7)}$. Clinical improvement is usually associated with a significant reduction in both the number of eosinophils and the levels of pro-inflammatory agents ${ }^{(7)}$. GC effects are mediated by activation of an intracellular receptor, namely the GC receptor ${ }^{(8)}$.

The possibility to isolate and culture cells such as fibroblasts from patients affected by airway diseases has greatly contributed to our understanding of the function of these cells in such diseases. In vitro cell cultures also provide a valuable tool for testing the efficacy of new or standard therapeutic treatments. The results obtained from these in vitro models may, however, strongly depend on the experimental methods used in the cell cultures. Supplementation of the culture medium with FBS is widely used to achieve the proper growth and proliferation of cells. In addition to this role, FBS is also commonly used as a non-specific stimulus of cytokine production in a variety of cell types ${ }^{(9)}$. It has been reported that endogenous steroids 
contained in FBS can limit cell sensitivity to exogenously added steroids ${ }^{(10,11)}$. For this reason, studies analysing GC action, such as the GC-induced translocation of the GC receptor, use charcoal-stripped FBS, i.e. FBS in which endogenous steroids have been removed by incubation with dextran-coated charcoal ${ }^{(12,13)}$. The effectiveness of this charcoal-stripped FBS in inducing cytokine release has, however, scarcely been investigated ${ }^{(14)}$, and, to our knowledge, no studies have reported its efficacy compared to FBS.

Serum starvation of the cell culture by pre-treatment of cells with FBS-free medium for 18 to $24 \mathrm{~h}$ prior to cell stimulation is often used in studies analysing cell proliferation and cytokine production and/or regulation by drug treatment in different cell types ${ }^{(9,15)}$. The effect of this step, which causes growth arrest of the cell culture, on cytokine production, and its influence on cell sensitivity to GC, is as yet unclear.

On the basis of the importance of cell culture methodology on the outcome of the inflammatory response in nasal polyp research, we first hypothesised that culture conditions have a relevant impact on cytokine production. We also hypothesised that nasal polyp fibroblasts produce greater amounts of cytokines, chemokines, and growth factors than a noninflamed nasal mucosa and have a diminished response to the inhibitory effects of GC.

Therefore, the objectives of this study were, first, to assess the role of culture conditions in the production of pro-inflammatory mediators by nasal polyp and nasal mucosa fibroblasts; secondly, to compare the levels of produced mediators between nasal polyp and nasal mucosa fibroblasts and, finally, to examine the response of these mediators to GC.

\section{MATERIALS AND METHODS}

\section{Subjects}

Nasal polyp tissue was obtained from 8 asthmatic subjects referred to the Hospital Clínic of Barcelona for sinus surgery (48 (mean) \pm 13 (SEM) yr; 5 men; 4 aspirin-intolerant). The study subjects were selected on the basis of a medical history consistent with severe nasal polyposis, as described in the $\mathrm{EP}^{3} \mathrm{OS}$ document ${ }^{(1)}$, and documented disease in their sinuses, as shown via CT scan ${ }^{(6)}$. All nasal polyp patients included herein had been followed up in the Rhinology Unit and Smell Clinic of our Hospital's ENT Department for at least one year prior to surgery, and were assigned for surgery because they had not shown any significant improvement in nasal obstruction, rhinorrhea, and/or quality of life, as described elsewhere ${ }^{(7,16)}$, after GC treatment. The diagnosis of asthma was established on the basis of the clinical history and the demonstration of a reversible bronchial obstruction, as previously reported ${ }^{(17)}$. Diagnosis of aspirin intolerance was made on the basis of a clear-cut history of asthma attacks precipitated by non-steroidal anti-inflammatory drugs (NSAID), and confirmed by aspirin nasal challenge in patients with an isolated episode of NSAID-induced asthma exacerba- tion, according to a method previously reported ${ }^{(18)}$. Nasal mucosa was obtained from the inferior turbinate of 8 subjects undergoing turbinectomy for turbinate hypertrophy with or without septoplasty for nasal septum deviation (35 (mean) \pm 10 (SEM) yr; 7 men). All patients with nasal polyps were on intranasal fluticasone or budesonide therapy, which was discontinued at least five days before surgery. No subjects in the nasal mucosa group had a history of nasal or sinus disease and they had not received GCs for any reason. None of the subjects had suffered from an upper respiratory infection in the two weeks prior to surgery. Subjects were asked their permission and informed consent was given to study the specimens under a protocol approved by the Ethics Committee of our hospital.

\section{Fibroblast isolation from nasal polyp and nasal mucosa}

Nasal tissues were cut into pieces and placed into 6-well plates (TPP, Switzerland) with Dulbecco's modified Eagle's medium (DMEM) containing 10\% Foetal Bovine Serum (FBS), $100 \mathrm{U} /$ $\mathrm{ml}$ penicillin, $100 \mu \mathrm{g} / \mathrm{ml}$ streptomycin and $2 \mu \mathrm{g} / \mathrm{ml}$ amphotericin B. Tissues were incubated in a humidified atmosphere at $37^{\circ} \mathrm{C}$ and $5 \% \mathrm{CO}_{2}$ for approximately 3 weeks, during which time fibroblasts migrated from the tissue and proliferated on the surface of the culture well. When $80 \%$ confluence was achieved, fibroblasts were then passaged in $150-\mathrm{cm}^{2}$ flasks. Experimental assays were carried out between passages 4 and 8. The fibroblast purity of the population was determined by immunocytochemistry against vimentin (V5255, Sigma) or pan-cytokeratin (C2562, Sigma), as previously reported ${ }^{(15,19)}$. After the second passage, $100 \%$ of both nasal mucosa and nasal polyp cell cultures were cytokeratin-negative and vimentin-positive. Fibroblast cultures were also tested for mycoplasma contamination using a PCR-based mycoplasma detection kit (VenorGeM, Minerva Biolabs).

\section{Fibroblast culture and treatment}

Cells were seeded into 24 -well plates at $3 \times 10^{4}$ cells/well, $1 \mathrm{ml} /$ well in DMEM supplemented with 10\% FBS for $24 \mathrm{~h}$. Then, cells were pre-treated with FBS-free DMEM or DMEM supplemented with either $10 \%$ FBS or 10\% charcoal-stripped FBS (csFBS, Invitrogen) for $24 \mathrm{~h}$. The incubation of nasal fibroblasts with FBS-free DMEM for 18 to $24 \mathrm{~h}$ provoked growth arrest, i.e. more than $90 \%$ of cells in G0/1 phase of the cell cycle, as determined by FACS analysis of propidium-iodidestained cells (data not shown). Cells pre-treated with FBS-free DMEM were then stimulated with either $10 \%$ FBS or $10 \%$ csFBS and cells pre-treated with FBS-supplemented medium were stimulated as in their pre-treatment. Dexamethasone (DEX, Fortecortin ${ }^{\mathrm{TM}}$, Merck) was added $1 \mathrm{~h}$ after the FBS stimuli at concentrations ranging from $10^{-10}$ to $10^{-6} \mathrm{M}$. Supernatants were collected at 4 and $24 \mathrm{~h}$ of DEX addition and stored at $-80^{\circ} \mathrm{C}$ until the cytokine measurement.

\section{Cell viability}

Cell viability after treatment was analysed by incubation of cells with the tetrazolium salt XTT (Cell Proliferation Kit II, 
XTT, Roche, Germany) for $3 \mathrm{~h}$, following the manufacturer's instructions. Absorbance was measured in duplicate at $490 \mathrm{~nm}$.

\section{Cytokine determination}

Human vascular endothelial growth factor (VEGF), granulocyte and monocyte colony stimulation factor (GM-CSF), interleukin (IL)-6 and IL-8 were quantified using a specific BD $^{\mathrm{TM}}$ Cytometric Bead Array (CBA) Flex Set (BD Biosciences, USA) using a FACS CANTO ${ }^{\text {TM }}$ Flow Cytometer (Becton Dickinson). Sensitivities of the assays were $<4.5 \mathrm{pg} / \mathrm{ml}$ for VEGF, $<0.2 \mathrm{pg} / \mathrm{ml}$ for GM-CSF, $<1.6 \mathrm{pg} / \mathrm{ml}$ for IL-6, and $<$ $1.2 \mathrm{pg} / \mathrm{ml}$ for IL-8. Concentrations were calculated on the basis of standard curves using the FCAP Array v1.0.1 software (Soft Flow, Inc). IL-6, IL-8 and VEGF levels were also measured by using commercial enzyme-linked immunosorbent assay (ELISA) DuoSet kits (R\&D Systems), according to the manufacturer's instructions. All samples were tested in duplicate and diluted until the cytokine level was within the linear range of the standard curve. The detection threshold was $10 \mathrm{pg} / \mathrm{ml}$ for each cytokine. Cytokine production was corrected by cell number as determined by the XTT assay. A good correlation was found between cytokine results measured by CBA and those measured by conventional ELISA $(r=0.97$; $<0.001)$.

\section{Statistical data analysis}

Data are given as median and $25^{\text {th }}$ to $75^{\text {th }}$ percentiles. Nonparametric statistical analysis was performed by using the Friedman test and Wilcoxon rank test for within-group comparisons, and the Kruskal-Wallis test and Mann-Whitney $U$ test for between-group comparisons. Rho Spearman's analysis was used to assess the correlation between CBA and ELISA measurements in IL-6 and IL-8 cytokine production. Statistical significance was set at $\mathrm{p}<0.05$.

\section{RESULTS}

Influence of growth arrest and serum on cytokine secretion We aimed to investigate the effect of growth arrest and serum on the release of cytokines by nasal mucosa and nasal polyp fibroblasts. To investigate the influence of growth arrest, cells were either pre-treated or otherwise; this pre-treatment - which provoked cell-cycle arrest - was undertaken with FBS-free DMEM for $24 \mathrm{~h}$. To investigate the influence of serum, cells were pre-treated and stimulated with DMEM supplemented with either $10 \%$ FBS or $10 \%$ charcoal-stripped-FBS (csFBS), which does not contain endogenous steroids. Cytokine release was measured in cell-culture supernatants by CBA after 0,4 and $24 \mathrm{~h}$ of FBS/csFBS stimulation.

Time-course experiments ( 0 to $24 \mathrm{~h}$ ) showed that, among the different mediators studied, IL- 8 and IL- 6 were the most abundant cytokines released by nasal fibroblasts, followed by VEGF (Figure 1). GM-CSF levels were below the detection threshold of the assay at both baseline and after $4 \mathrm{~h}$ of any treatment, its levels being only detectable in growth-arrested cells stimulated with FBS for $24 \mathrm{~h}$ (nasal mucosa: 7.4 (median); 2 - 10.7 ( $25^{\text {th }}-75^{\text {th }}$ percentiles) $\mathrm{pg} / \mathrm{ml}$ and nasal polyp: $3.4 ; 1.3-6 \mathrm{pg} / \mathrm{ml}$; ns).

As shown in Figure 1, the highest induction of IL-8, IL-6 and VEGF over time for both nasal mucosa and nasal polyp fibroblasts was found in growth-arrested cells stimulated with $10 \%$ FBS. Using this same stimulus, cytokine production in non-growth-arrested cells was much lower than that in growtharrested cells. In both growth-arrested and non-growth-arrested cells, stimulation with csFBS provoked a poor induction of all cytokines compared to FBS-stimulated cells. The lowest cytokine levels for both nasal mucosa and nasal polyp fibroblasts were found in non-growth-arrested cells stimulated with csFBS (Figure 1).

At the time of maximal induction of cytokine production by the stimulus, i.e. $24 \mathrm{~h}$, IL- 8 production was higher in nasal polyp than in nasal mucosa fibroblasts in all the cell-culture conditions tested, this difference being particularly marked $(\mathrm{p}<0.05)$ in growth-arrested cells stimulated with 10\% FBS (Figure 1). No significant differences were found in GM-CSF, VEGF and IL-6 production between nasal mucosa and nasal polyp fibroblasts for any of the experimental conditions tested.

\section{$I L-8, I L-6$ and VEGF production in response to dexamethasone}

Since maximal cytokine secretion was found in growth-arrested cells with $10 \%$ FBS as a stimulus, we studied the effect of DEX in these conditions and calculated the inhibitory concentration needed to cause a $25 \%$ cytokine inhibition $\left(\mathrm{IC}_{25}\right.$ ) in all the samples. To minimise the high inter-individual variability in

Table 1. Effect of growth-arrest and serum stimulation for 4 and $24 \mathrm{~h}$ on fibroblast viability.

\begin{tabular}{lccrr}
\hline & \multicolumn{4}{c}{ Absorbance $\left(\mathrm{A}_{490}\right) \mathrm{nm}$} \\
\cline { 2 - 5 } Cell culture conditions & \multicolumn{2}{c}{ Nasal Mucosa } & \multicolumn{3}{c}{ Nasal Polyp } \\
\cline { 2 - 5 } GA_FBS & $1.3(1.0-2.3)$ & $1.9(1.4-2.4)$ & $1.5(1.3-2.1)$ & $24 \mathrm{~h}$ \\
GA_csFBS & $1.9(1.2-2.3)$ & $2.1(1.4-2.4)$ & $1.6(1.2-2.1)$ & $1.8(1.6-2.0)$ \\
Non-GA_FBS & $1.3(0.7-2.5)$ & $1.9(1.0-2.5)$ & $1.3(1.3-2.1)$ & $2.0(1.8-2.2)$ \\
Non-GA_csFBS & $1.2(0.8-2.5)$ & $2.0(1.6-2.4)$ & $1.3(1.1-2.0)$ & $2.2(1.8-2.3)$ \\
\hline
\end{tabular}

Results are expressed as median and $25^{\text {th }}-75^{\text {th }}$ percentiles. GA, Growth-arrest; Non-GA, non-growth-arrest; FBS, Foetal Bovine Serum; csFBS, charcoal-stripped FBS. 


\section{Nasal Mucosa}

A

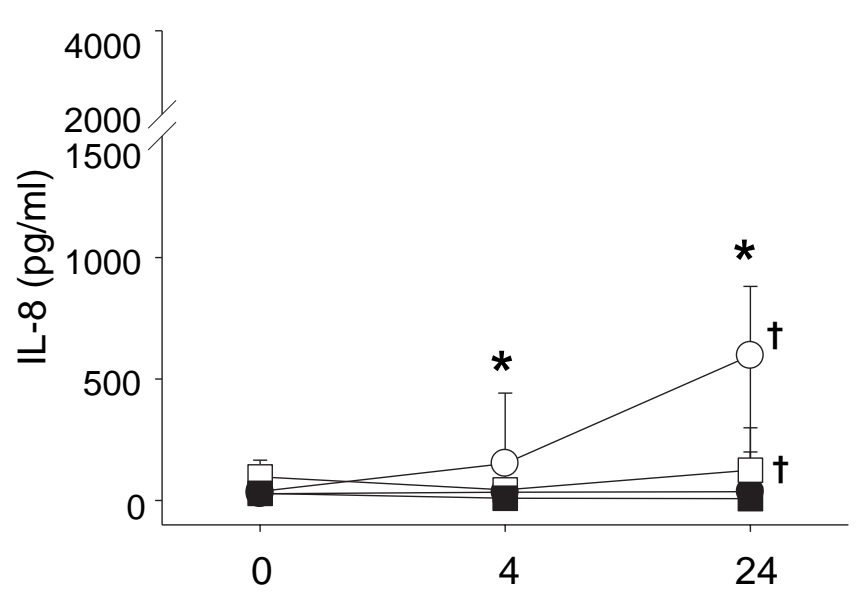

B
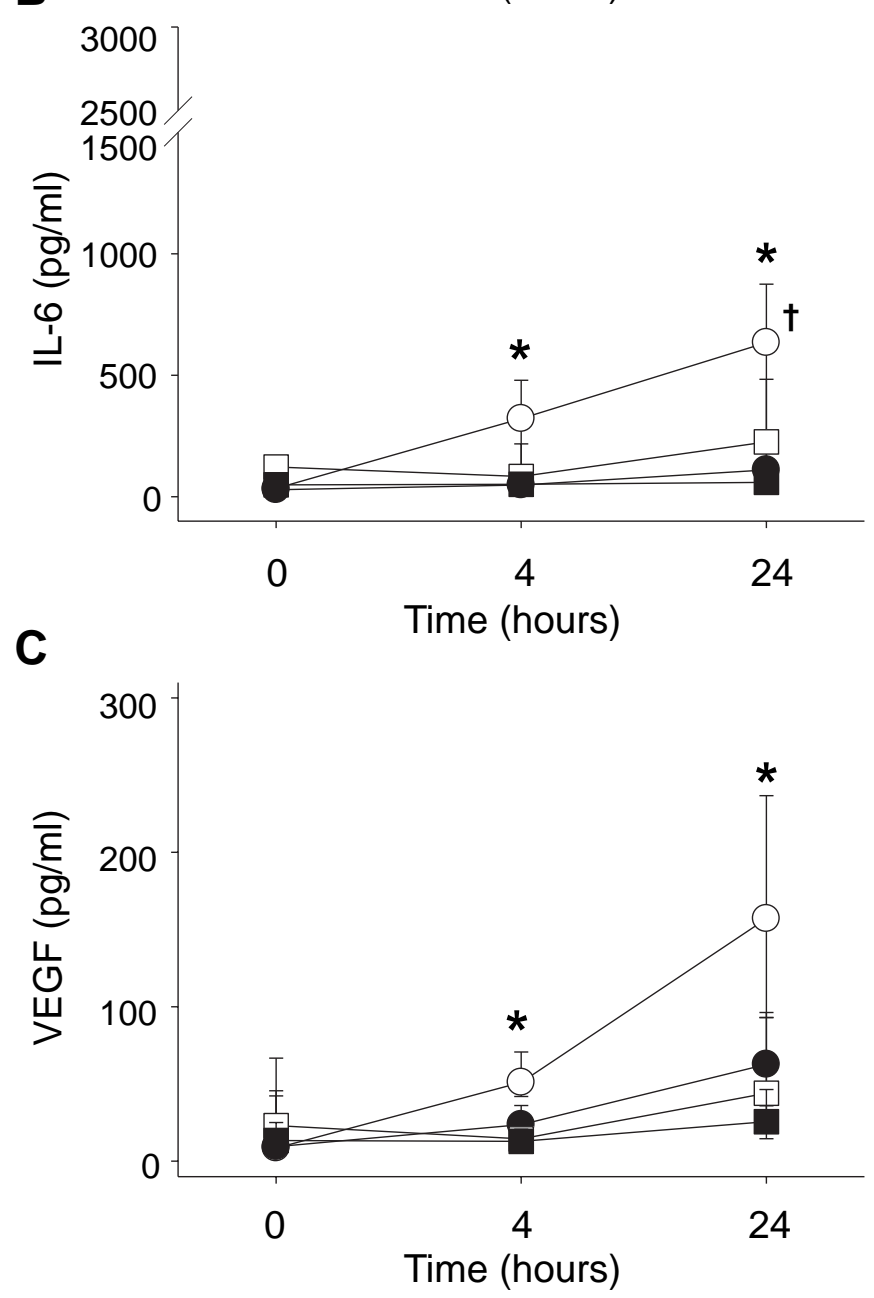

Nasal Polyp
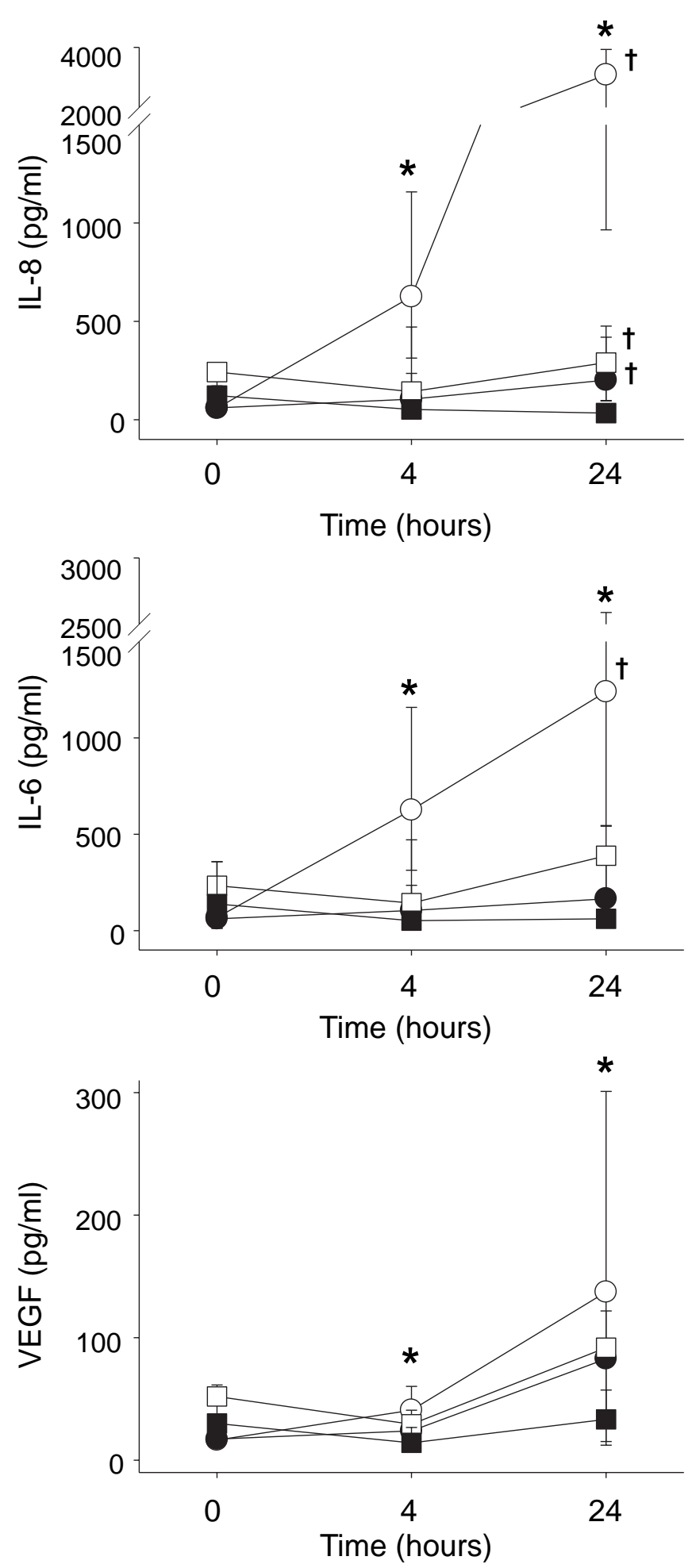

\section{-O- GA FBS \\ - GA_csFBS \\ $-\square-$ nonGA_FBS}

Figure 1. Effect of growth arrest and serum on IL-8, IL-6 and VEGF secretion. The effect of growth arrest and serum on the secretion of IL-8 (A), IL-6 (B), and VEGF (C) was analysed in nasal mucosa (left graphs) and nasal polyp fibroblasts (right graphs). Fibroblasts were either growth-arrested (GA), by pre-treatment with FBS-free DMEM, or non-growth-arrested (Non-GA), by pre-treatment with 10\% FBS or 10\% charcoal-stripped FBS (csFBS), for $24 \mathrm{~h}$. Cells were then stimulated with either FBS or csFBS for 4 and $24 \mathrm{~h}$. Supernatants were collected and assessed for cytokine production. Results are expressed as median and $25^{\text {th }}-75^{\text {th }}$ percentile values. ${ }^{*}, \mathrm{p}<0.05$ compared to $0 \mathrm{~h}$; and $\dagger, \mathrm{p}<0.05$ compared to $4 \mathrm{~h}$ by Wilcoxon test. 
A

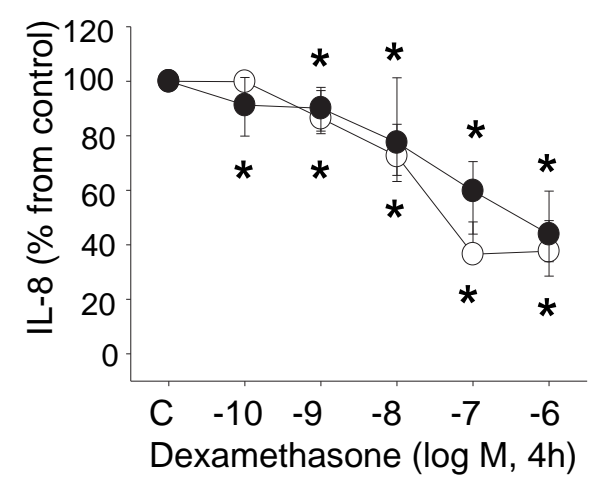

C

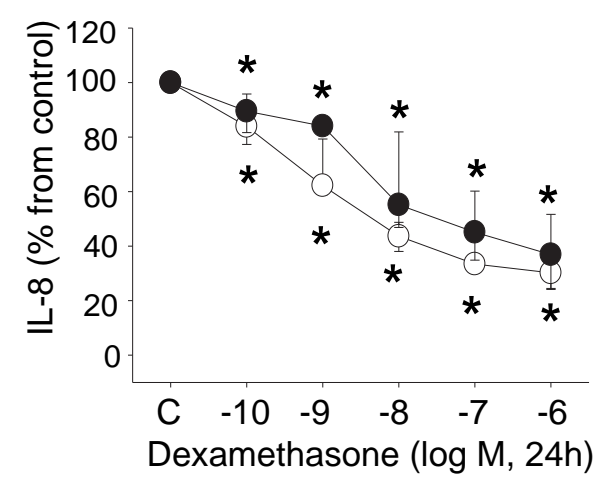

B

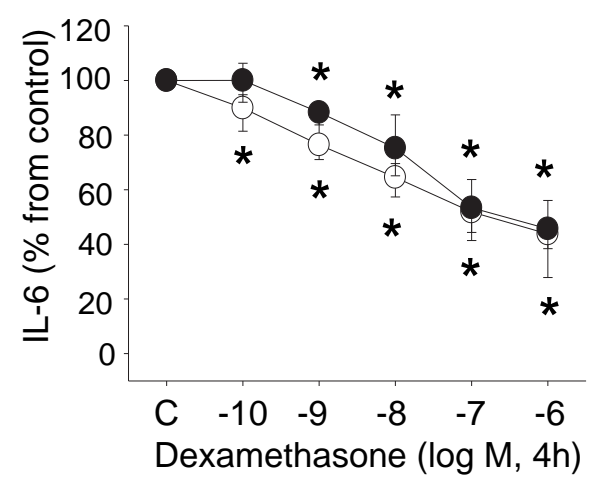

D

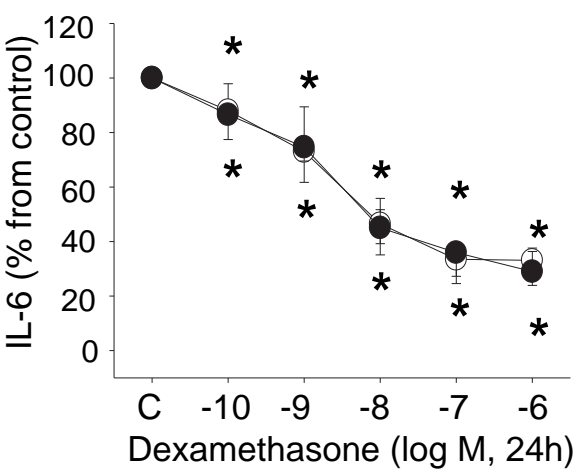

$\mathbf{E}$

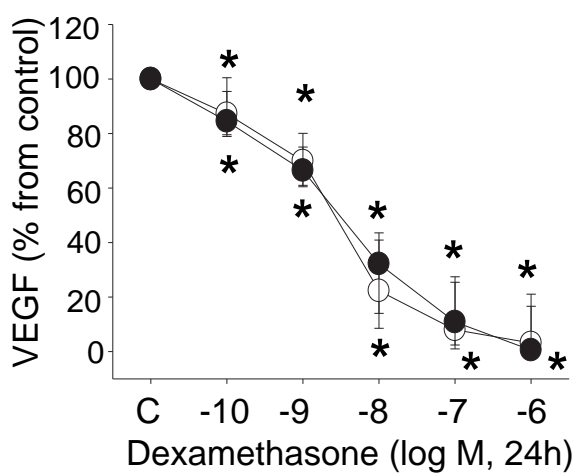

Figure 2. Effect of dexamethasone on IL-8, IL-6 and VEGF secretion. The effect of dexamethasone on IL-8 (A,C), IL-6 (B,D) and VEGF (E) secretion was analysed in nasal mucosa and nasal polyp fibroblasts. Fibroblasts were growth-arrested and then exposed to $10 \%$ FBS (control, C) and increasing amounts of dexamethasone $\left(10^{-10}\right.$ to $\left.10^{-6} \mathrm{M}\right)$ for $4 \mathrm{~h}(\mathrm{~A}, \mathrm{~B})$ and $24 \mathrm{~h}(\mathrm{C}$-E). Cytokine production (in pg/ml) was corrected by cell number and normalised to control (non-DEX-treated cells: $100 \%$ ). Results are expressed as median and $25^{\text {th }}-75^{\text {th }}$ percentile values. $*$ p $<0.05$ compared to control (C) by Wilcoxon.

cytokine release upon FBS stimulation (Figure 1) and to optimally visualise the effect of DEX on cytokine release, cytokine production ( $\mathrm{pg} / \mathrm{ml}$ corrected by cell number) at each DEX concentration was normalised to control (non-DEX-treated) cells $(100 \%)$ for each specimen. As shown in Figure 2, DEX treatment for $4 \mathrm{~h}$ inhibited IL-8 (Figure 2A) and IL-6 secretion (Figure 2B) in a dose-dependent manner in both nasal mucosa (8; 1.7-28.3 nM for IL-8 and 1.8; 0.8-4.2 nM for IL-6) and nasal polyp fibroblasts $(17.3 ; 1.2-50.6 \mathrm{nM}$ for IL-8 and 6,$5 ; 3.5-17.1 \mathrm{nM}$ for IL-6), without any statistically significant differences in the $\mathrm{IC}_{25}$ for IL- 6 and IL- 8 between nasal mucosa and nasal polyp fibroblasts.

After $24 \mathrm{~h}$ of DEX treatment, the release of IL-8 (Figure 2C), IL-6 (Figure 2D) and VEGF (Figure 2E) was also dosedependently inhibited in both nasal mucosa $(0.3 ; 0.1-1.6$ $\mathrm{nM}$ for IL-8, 0.7; 0.5-1.1 nM for IL-6 and 0.8; 0.2-1.2 nM for VEGF) and nasal polyp fibroblasts $(1.4 ; 0.9-10.4 \mathrm{nM}$ for IL-8, 0.9; 0.5-2.9 $\mathrm{nM}$ for IL-6 and 0.5; 0.4-0.9 $\mathrm{nM}$ for VEGF). At this time-point, DEX provoked a similar reduction of IL-6 and VEGF in both nasal mucosa and nasal polyp fibroblasts, whereas DEX was less effective in inhibiting IL-8 release in nasal polyp compared to nasal mucosa fibroblasts $(\mathrm{p}<0.05)$.

Effect of culture conditions and dexamethasone on cell viability Because viability can alter the biosynthetic capacity of cells, we assessed whether the effects of growth arrest, serum and DEX on cytokine production were caused by the induction of cytotoxicity as measured by the Cell Proliferation Assay (XTT). There were no significant changes in the $A_{490 n m}$ values between FBS- and csFBS-treated cells, or between growth-arrested and non-growth-arrested cells, either at $4 \mathrm{~h}$ or $24 \mathrm{~h}$ (Table 1). Furthermore, no significant differences in $\mathrm{A}_{490 \mathrm{~nm}}$ values were found after DEX treatment, indicating that DEX did not induce cytotoxicity in nasal fibroblasts (Figure 3 ).

\section{DISCUSSION}

Since the methodology used in in vitro cell culture models of nasal polyposis may have a relevant impact on the outcome of the inflammatory response in nasal polyp research, the main aim of our study was to assess the role of culture conditions in the production of pro-inflammatory mediators by nasal polyp and nasal mucosa fibroblasts. We show that both nasal 


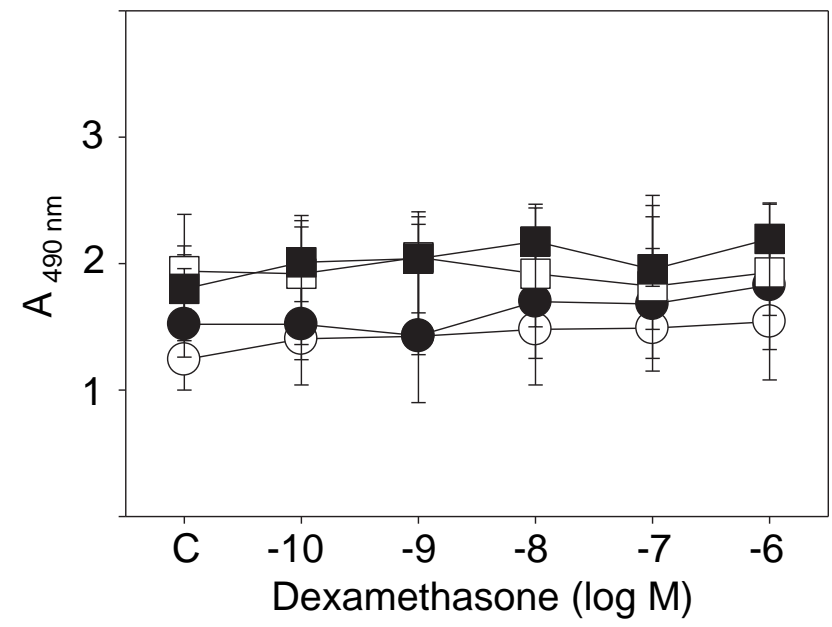

polyp and nasal mucosa fibroblasts release IL-6, IL-8, VEGF and GM-CSF and that the production of these mediators is significantly affected by the cell-culture conditions used. In particular, both the type of FBS used to stimulate the cells and the pre-treatment, or otherwise, of the cell culture with FBS-free medium $(24 \mathrm{~h})$ prior to cell stimulation have a significant impact on the release of these mediators. We report that growth-arrested cells stimulated with $10 \%$ FBS provide the ideal conditions for inducing maximal production of cytokines by both nasal mucosa and nasal polyp fibroblasts.

csFBS has been used in studies that examine the mechanisms of steroid-receptor activation upon hormone binding ${ }^{(10,12,20)}$ to avoid that endogenous steroids contained in FBS can limit cell sensitivity to exogenously added steroids. In fact, Ouatas and coworkers ${ }^{(10)}$ and Berteaux and coworkers ${ }^{(11)}$ reported a lack of induction of steroid-responsive genes in cell lines cultured with the steroid in the presence of serum-containing medium, while cells were responsive to the steroid in serum-stripped medium. However, while maximal response is achieved in these studies using csFBS, we found that csFBS is a much weaker inducer of cytokine production compared to FBS. This suggests that charcoal-stripping of serum may have removed stimulators required for nasal fibroblasts to induce cytokine release. One of such removed stimulators might be the estrogen $17 \beta$-estradiol (21). This hormone is reported to increase IL-6, IL-8 or VEGF release by different in vitro cultured cell types, including fibroblasts ${ }^{(22-25)}$. We could speculate that removal of estradiol from FBS could be at least partly responsible for the poor induction of cytokine release by csFBS compared to FBS in our cells. All in all, these observations should be taken into account when using csFBS as a stimulus for in vitro cell culture studies.

We also show that proliferating (non-growth-arrested) cells produce much fewer cytokines and growth factors upon stimulation than cells that have been growth-arrested prior to stimulation, indicating that growth arrest of the cell culture is required to obtain maximal responsiveness. There are almost no studies specifically reporting the benefits of doing growth arrest versus not doing it on cytokine production. However,

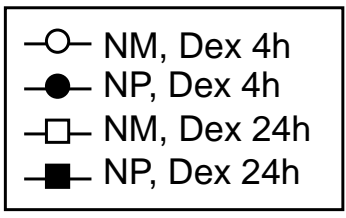

Figure 3. Dexamethasone does not alter nasal fibroblasts' viability. The effect of dexamethasone on cell viability in nasal mucosa (NM, open symbols) and nasal polyp (NP, filled symbols) fibroblasts was analysed. Cells were growth-arrested and then exposed to $10 \%$ FBS (control, C) and increasing amounts of dexamethasone $\left(10^{-10}\right.$ to $\left.10^{-6} \mathrm{M}\right)$ for 4 and $24 \mathrm{~h}$. Results are expressed as median and $25^{\text {th }}-75^{\text {th }}$ percentile values.

similarly to our findings, one study ${ }^{(26)}$ reports that transcription of the cytokine-inducible gene cylooxygenase-2 (COX-2) is suppressed in proliferating versus quiescent fibroblasts. The author argues that an array of other genes, in addition to COX-2, is likely to be suppressed in proliferating cells, and further postulates that suppression of stress-induced expression of proinflammatory genes such as COX-2 in proliferating cells helps reduce the generation of DNA-damaging oxidants.

Among the cytokines analysed in this study, IL-6 and IL-8, which are involved in the regulation of inflammatory responses ${ }^{(27-29)}$, are the ones released in greatest amounts by both nasal mucosa and nasal polyp fibroblasts. Only the levels of IL-8, however, were significantly increased in nasal polyp compared with nasal mucosa fibroblasts. Increased production of IL-8 has also been reported in in vitro cultured nasal polyp epithelial cells ${ }^{(27)}$ and in nasal polyp cells and tissues compared to controls ${ }^{(30,31)}$. The present study suggests that fibroblasts can contribute to the increased production of IL-8 detected in vivo in patients with nasal polyps.

VEGF is increased in asthmatic airways ${ }^{(32)}$ and correlates directly with disease activity and inversely with airway calibre and airway responsiveness ${ }^{(33,34)}$. Similarly, VEGF has been found increased in nasal polyps, compared with nasal mucosa tissues ${ }^{(35)}$, and has been implicated in the development of nasal polyp hyperplasic epithelium ${ }^{(36)}$. However, we did not find significant differences in VEGF production between nasal mucosa and nasal polyp fibroblasts.

GCs, the most effective medication used in long-term treatment of nasal polyps, modulate many fibroblasts' functions, including secretion of cytokines and growth factors ${ }^{37,38)}$. In agreement with previous studies ${ }^{(15,39,40)}$, GCs inhibited the FBS-induced release of IL-6, IL- 8 and VEGF in a dose- and time-dependent manner in nasal mucosa and nasal polyp fibroblasts. Sensitivity to the DEX-mediated inhibition of IL-6 and VEGF production did not differ between nasal mucosa and nasal polyp fibroblasts. On the other hand, nasal polyp fibroblasts appeared to be less sensitive (higher $\mathrm{IC}_{25}$ ) to DEX- 
mediated inhibition of IL-8 compared with nasal mucosa fibroblasts. The slightly lower sensitivity of nasal polyp fibroblasts to DEX inhibitory effects might be the result of their higher IL-8 production. The biological significance of this finding, however, remains to be determined.

Finally, we demonstrate that differences in cytokine production among the different experimental treatments are not related to changes in cell viability.

In summary, we report that growth-arrested cells stimulated with $10 \%$ FBS provide the ideal conditions for inducing maximal production of IL-6, IL-8, VEGF, and GM-CSF by nasal polyp and nasal mucosa fibroblasts. We also found that IL-6 and IL-8 were the cytokines produced in the greatest amounts, although only IL-8 levels were significantly greater in nasal polyp than in nasal mucosa fibroblasts. DEX reduced the production of all cytokines in both nasal polyp and nasal mucosa fibroblasts, although nasal polyp fibroblasts were slightly less sensitive to DEX-mediated inhibition of IL-8 compared to nasal mucosa fibroblasts. In conclusion, our study demonstrates that the production of cytokines by in vitro cultured nasal fibroblasts is significantly affected by the culture conditions used and is inhibited by dexamethasone in both fibroblast types. Our results ultimately highlight the importance of culture methodology on nasal polyp research outcomes.

\section{ACKNOWLEDGEMENTS}

We thank Isabel Crespo, Cytometry Unit, Hospital Clínic, who provided technical assistance in the CBA analysis. This study was supported by grants from Fondo de Investigación Sanitaria (050057 and 080419) and Fundació Catalana de Pneumologia (FUCAP). The research activity of L Pujols is supported by Instituto de Salud Carlos III - Fondo de Investigación Sanitaria (050149). L Fernández-Bertolín was the recipient of a predoctoral fellowship grant from IDIBAPS.

\section{AUTHOR CONTRIBUTIONS}

LFB contributed to the design of the study and performed the experiments, the techniques and the interpretation and statistical analysis of data. She was fully involved in the drafting and revision of this manuscript together with CP and LP. JM contributed to the design of the study and provided critical revision of both data and manuscript. IA provided the surgical specimens needed to perform the study. JRF provided methodological and technical assistance, and contributed to the design of some experiments. CP contributed to the conception and design of the study, and co-directed the study together with LP. LP participated in the interpretation and statistical analysis of data together with LFB. All authors read and approved the final manuscript.

\section{CONFLICT OF INTEREST}

None of the authors has a conflict of interest to declare in relation to this work.

\section{REFERENCES}

1. Fokkens W, Lund V, Mullol J. on behalf of the European Position Paper on Rhinosinusitis and Nasal Polyp Group. European position paper on rhinosinusitis and nasal polyps 2007. Rhinology 2007; Suppl 20: 1-136.

2. Pawliczak R, Lewandowska-Polak A, Kowalski ML. Pathogenesis of nasal polyps: an update. Curr Allergy Asthma Rep 2005; 5: 463-471.

3. Otto BA, Wenzel SE. The role of cytokines in chronic rhinosinusitis with nasal polyps. Curr Opin Otolaryngol Head Neck Surg 2008; 16: 270-274.

4. Smith RS, Smith TJ, Blieden TM, Phipps RP. Fibroblasts as sentinel cells. Synthesis of chemokines and regulation of inflammation. Am J Pathol 1997; 151: 317-322.

5. Olsson S, Cagnoni F, Dignetti P, Melioli G, Canonica GW. Low concentrations of cytokines produced by allergen-stimulated peripheral blood mononuclear cells have potent effects on nasal polyp-derived fibroblasts. Clin Exp Immunol 2003; 132: 254-260.

6. Benítez P, Alobid I, de Haro J, et al. A short course of oral prednisone followed by intranasal budesonide is an effective treatment of severe nasal polyps. Laryngoscope 2006; 116: 770-775.

7. Fokkens W. Role of steroids in the treatment of rhinosinusitis with and without polyposis. Clin Allergy Immunol 2007; 20: 241-250.

8. Pujols L, Mullol J, Torrego A, Picado C. Glucocorticoid receptors in human airways. Allergy 2004; 59: 1042-1052.

9. Yang JQ, Rüdiger JJ, Hughes JM, et al. Cell density and serum exposure modify the function of the glucocorticoid receptor $\mathrm{C} /$ EBP complex. Am J Respir Cell Mol Biol 2008; 38: 414-422.

10. Ouatas T, Halverson D, Steeg PS. Dexamethasone and medroxyprogesterone acetate elevate $\mathrm{Nm} 23-\mathrm{H} 1$ metastasis suppressor gene expression in metastatic human breast carcinoma cells; new uses for old compounds. Clin Cancer Res 2003; 10: 3763-3772.

11. Berteaux N, Lottin S, Adriaenssens E, et al. Hormonal regulation of $\mathrm{H} 19$ gene expression in prostate epithelial cells. J Endocrinol 2004; 183: 69-78.

12. Goleva E, Li LB, Eves PT, Strand MJ, Martin RJ, Leung DM. Increased glucocorticoid receptor $\beta$ alters steroid response in glucocorticoid-insensitive asthma. Am J Respir Crit Care Med 2006; 173: 607-616.

13. Pariante CM, Pearce BD, Pisell TL, et al. The proinflammatory cytokine, interleukin-1alpha, reduces glucocorticoid receptor translocation and function. Endocrinology 1999; 140: 4359-4366.

14. Rosen T, Krikun G, MA Y, Wang E, Lockwood CJ, Guller S. Chronic antagonism of nuclear factor-kappaB activity in cytotrophoblasts by dexamethasone: A potential mechanism for antiinflammatory action of glucocorticoids in human placenta. J Clin Endocrinol Metab 1998; 83: 3647-3652.

15. Pujols L, Fuentes-Prado M, Fernández-Bertolín L, et al. Lower sensitivity of nasal polyp fibroblasts to glucocorticoid anti-proliferative effects. Respir Med 2011; 105: 218-225.

16. Alobid I, Benítez P, Bernal-Sprekelsen M, et al. Nasal polyposis and its impact on quality of life: comparison between the effects of medical and surgical treatments. Allergy 2005; 60: 452-458.

17. Torrego A, Pujols L, Roca-Ferrer J, Mullol J, Xaubet A, Picado C. Glucocorticoid receptor isoforms alpha and beta in in vitro cytokine-induced glucocorticoid insensitivity. Am J Respir Crit Care Med 2004; 170: 420-425.

18. Casadevall J, Ventura PJ, Mullol J, Picado C. Intranasal challenge with aspirin in the diagnosis of aspirin intolerant asthma: evaluation of nasal response by acoustic rhinometry. Thorax 2000; 55: 921-924.

19. Roca-Ferrer J, Garcia-Garcia FJ, Pereda J, et al. Nasal polyps and aspirin-intolerant patients produce little prostaglandin E2 and have reduced expression of cyclooxygenases. J Allergy Clin Immunol. 2011; 128: 66-72.

20. Galliher-Beckley AJ, Williams JG, Collins JB, Cidlowski JA. Glycogen synthase kinase 3beta-mediated serine phosphorylation of the human glucocorticoid receptor redirects gene expression profiles. Mol Cell Biol 2008; 24: 7309-7322.

21. Dang ZC, Lowik CWGM. Removal of serum factors by charcoal treatment promotes adipogenesis via a MAPK-dependent pathway. Mol Cell Biochem 2005; 268: 159-167. 
22. Bendrik C, Dabrosin C. Estradiol increases IL-8 secretion of normal human breast tissue and breast cancer in vivo. J Immunol 2009; 182: 371-378.

23. Bengtsson AK, Ryan EJ, Giordano D, Magaletti DM, Clark EA. 17beta-Estradiol (E2) modulates cytokine and chemokine expression in human monocyte-derived dendritic cells. Blood 2004; 104 : 1404-1410.

24. Dabrosin C, Margetts PJ, Gauldie J. Estradiol increases extracellular levels of vascular endothelial growth factor in vivo in murine mammary cancer. Int J Cancer 2003; 107: 535-540.

25. Classen-Linke I, Alfer J, Krusche CA, Chwalisz K, Rath W, Beier HM. Progestins, progesterone receptor modulators, and progesterone antagonists change VEGF release of endometrial cells in culture. Steroids 2000; 65: 763-771.

26. Wu KK. Differential cyclooxygenase-2 transcriptional control in proliferating versus quiescent fibroblasts. Prostaglandins Other Lipid Mediat 2007; 83: 175-181.

27. Mullol J, Xaubet A, Gaya A, et al. Cytokine gene expression and release from epithelial cells. A comparison study between healthy nasal mucosa and nasal polyps. Clin Exp Allergy 1995; 25: 607-615.

28. Malerba M, Ricciardolo F, Radaeli A, et al. Neutrophilic inflammation and IL-8 levels in induced sputum of alpha-1-antitrypsin PiMZ subjects. Thorax 2006; 61: 129-133.

29. Sehmi R, Cromwell O, Wardlaw J. IL-8 is a chemoattractant for eosinophils purified from subjects with a blood eosinophilia but not from healthy subjects. Clin Exp Allergy 1994; 23: 1027-1031.

30. Lennard CM, Mann EA, Sun LL, Chang AS, Bolger WE. Interleukin-1 beta, interleukin-5, interleukin-6, interleukin- 8 and tumor necrosis factor-alpha in chronic sinusitis: response to systemic corticosteroids. Am J Rhinol 2000; 14: 367-373.

31. Kostamo K, Sorsa T, Leino M, et al. In vivo relationship between collagenase-2 and interleukin-8 but not tumour necrosis factoralpha in chronic rhinosinusitis with nasal polyposis. Allergy 2005; 60: $1275-1279$.

32. Asai K, Kanazawa H, Kamoi H, Shiraishi S, Hirata K, Yoshikawa J. Increased levels of vascular endothelial growth factor in induced sputum in asthmatic patients. Clin Exp Allergy 2003; 33: 595-599.

33. Hoshino M, Takahashi M, Aoike N. Expression of vascular endothelial growth factor, basic fibroblast growth factor, and angiogenin immunoreactivity in asthmatic airways and its relationship to angiogenesis. J Allergy Clin Immunol 2001; 107: 295-301.

34. Lee YC, Lee HK. Vascular endothelial growth factor in patients with acute asthma. J Allergy Clin Immunol 2001; 107: 1106.
35. Gosepath J, Brieger J, Lehr HA, Mann WJ. Expression, localization and significance of vascular permeability/vascular endothelial growth factor in nasal polyps. Am J Rhinol 2005; 19: 7-13.

36. Lee HS, Myers A, Kim J. Vascular endothelial growth factor drives autocrine epithelial cell proliferation and survival in chronic rhinosinusitis with nasal polyposis. Am J Respir Crit Care Med 2009; 180: 1056-1067.

37. Silvestri M, Sabatini F, Scarso L, Cordone A, Dasic G, Rossi GA. Fluticasone propionate downregulates nasal fibroblast functions involved in airway inflammation and remodelling. Int Arch Allergy immunol 2002; 128: 51-58.

38. Tobler A, Meier R, Seitz M, Dewald B, Baggiolini M, Fey MF. Glucocorticoids downregulate gene expression of GM-CSF, NAP-1/IL-8, and IL-6, but not of M-CSF in human fibroblasts. Blood 1992; 79: 45-51.

39. Nauck M, Roth $\mathbf{M}$, Tamm M, et al. Induction of vascular endothelial growth factor by platelet-activating factor and platelet-derived growth factor is downregulated by corticosteroids. Am J Respir Cell Mol Biol 1997; 16: 398-406.

40. Pelaia G, Gallelli L, D'Agostino B, et al. Effects of TGF-beta and glucocorticoids on map kinase phosphorylation, IL-6/IL-11 secretion and cell proliferation in primary cultures of human lung fibroblasts. J Cell Physiol 2007; 210: 489-497.

Laura Pujols

Institut d'Investigacions Biomèdiques August Pi i Sunyer (IDIBAPS)

lab 402

Hospital Clínic

Villarroel 170

08036, Barcelona

Catalonia

Spain

Tel: +34-93-227 5400 (ext. 3282)

Fax: +34-93-451 5272

E-mail:1pujols@clinic.ub.e

\section{ADVERTISEMENT}

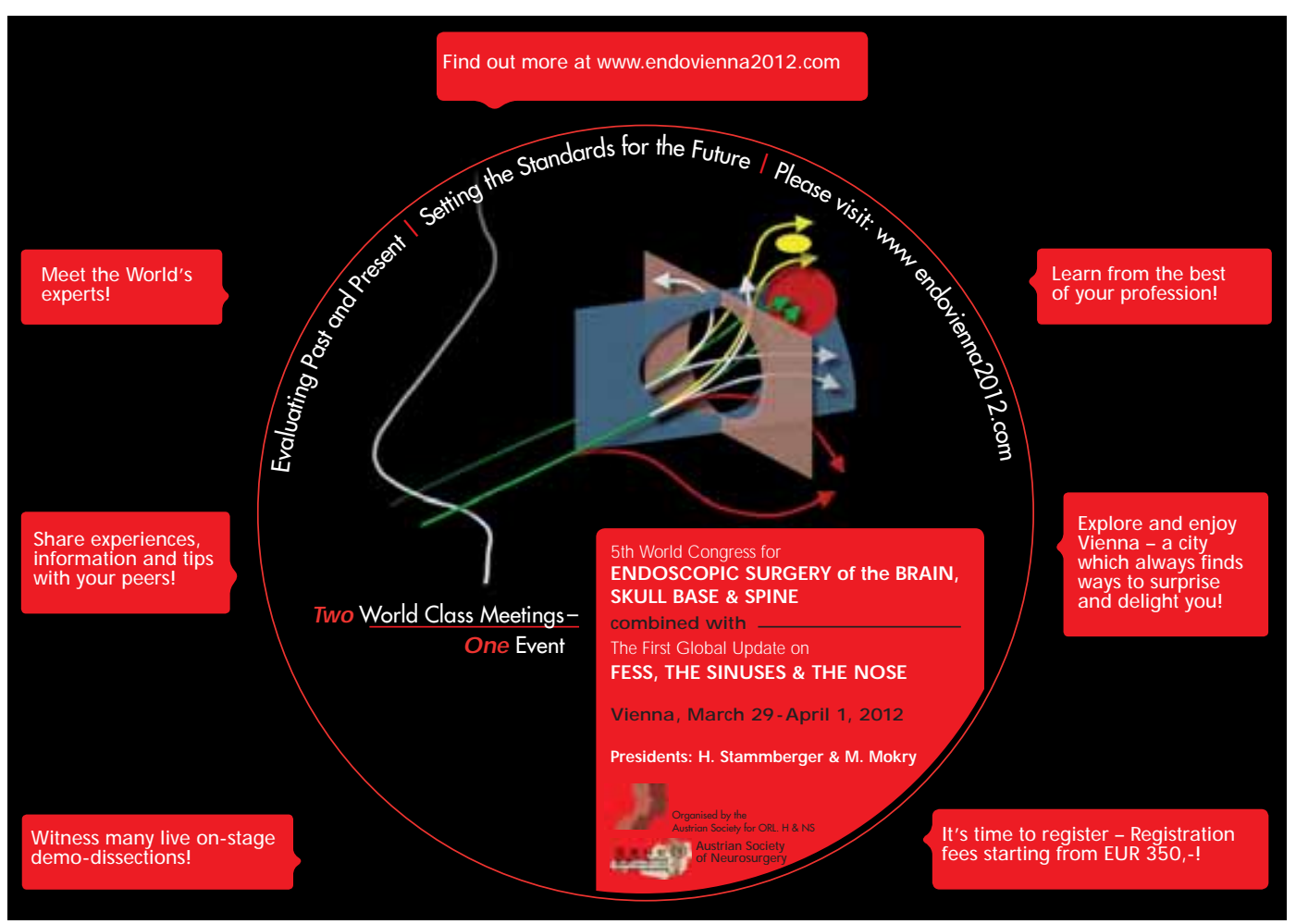

